\title{
Gas Transport Properties of Asymmetric Block Copolyimide Membranes
}

\author{
By Yumi KaShimura, Satoshi AoyAmA, and Hiroyoshi KAWAKAMI*
}

\begin{abstract}
We have synthesized fluorinated block copolyimides with different block chain lengths by chemical imidization in a two-pot procedure and prepared the asymmetric coployimide membranes using the dry-wet phase inversion process. The gas transport properties of the asymmetric membranes were measured using a high vacuum apparatus equipped with a Baratron absolute pressure gauge at $76 \mathrm{cmHg}$ and $35^{\circ} \mathrm{C}$. We demonstrated that the skin layer thicknesses and the gas transport properties of the asymmetric membranes depended on the copolyimide structures. The phase separation in the block copolyimide solution instantaneously occurred so that the skin layer of the asymmetric block copolyimide membrane became thinner than that of the asymmetric random copolyimide membrane and the gas permeance of the asymmetric block copolyimide membrane had a high value. The apparent skin layer thickness of the asymmetric block coployimide membrane was $230 \mathrm{~nm}$. The asymmetric copolyimide membrane indicated an $\mathrm{O}_{2}$ permeance of $2.7 \times 10^{-4}\left[\mathrm{~cm}^{3}(\mathrm{STP}) /\left(\mathrm{cm}^{2} \mathrm{sec} \mathrm{cmHg}\right)\right](270[\mathrm{GPU}])$ and an $\mathrm{O}_{2} / \mathrm{N}_{2}$ selectivity of 4.3 .
\end{abstract}

KEY WORDS: Asymmetric Membrane / Block Copolymer / Gas Transport / Dry-Wet Phase Inversion / Skin Layer /

Polymer membranes are considered an effective technology for the separation of gaseous mixtures due to their high separation efficiency, low operating costs, and simple operation. The development of novel polymer membranes with even higher gas permeabilities and selectivities has received much attention. ${ }^{1,2}$ The gas permeation through a polymer membrane not only is a function of the chemical structure of the polymers but also is determined by the morphology or the domain structure formed on the membrane. Particularly, in the case of the block copolymers or miscible blends of polymers, their gas permeations are affected by the domain size of microor nanometers formed on the membrane or the extent of the interactions between the component polymers. ${ }^{3-5}$ Recently, the gas transport properties of block copolymers based on a rubbery polymer have been investigated for acid gas removal from natural gas, recovery of $\mathrm{CO}_{2}$ from flue gases, and the removal of $\mathrm{CO}_{2}$ from gas mixtures with hydrogen. ${ }^{6}$ However, it is difficult to prepare ultrathin membranes from the block copolymers based on rubbery polymers, because these copolymers do not have sufficient mechanical properties.

Polyimide as a glassy polymer has been recognized as one of the most promising potential candidates for a gas separation material because of the high gas selectivity and excellent mechanical properties for preparing the ultrathin membranes. $^{7-9}$ In general, the polyimide is obtained from a precursor condensed from two monomers with dianhydride and diamine moieties, and the gas transport properties through the polyimide membrane have been investigated. Although the gas transport properties of copolyimide membranes were reported in some papers, ${ }^{10-12}$ most of the copolyimides were random copolymers and there has been little attention given to the gas transport properties of block copolyimide membranes.
Of course, there are a few papers concerning block copolyimides, which reported the effects of the monomer structure and the length of the block chains on the thermal and chemical stability or mechanical properties of the copolyimide. ${ }^{13,14}$ However, little attention has been paid to preparing an asymmetric polymer membrane with an ultrathin and defectfree skin layer from the copolyimide.

Phase separation is in wide use today to fabricate an asymmetric polymer membrane for gas separation. ${ }^{15,16}$ Currently, the process is used to prepare membranes mainly from homopolymers. We also prepared an asymmetric polyimide membrane with a thin, defect-free skin layer using the dry-wet phase inversion process, which is formed using three components (a ternary system), i.e., polymer/solvent/non-solvent. ${ }^{17-20}$ The asymmetric membranes were cast from homopolyimide/ dichloromethane/1,1,2-trichloroethane/butanol. The phase inversion process involves the phase separation of a polymer solution in polymer-rich and -lean phases, which can be achieved by an immersion-precipitation technique. ${ }^{18} \mathrm{We}$ succeeded in preparing an asymmetric polyimide membrane with an ultrathin (approximately $10 \mathrm{~nm}$ ) and defect-free skin layer using the phase separation technique. Although the block copolymer appears to display interesting phase separation behavior for the immersion precipitation, few studies regarding the fabrication of an asymmetric membrane from the copolymer using this technique have been reported.

In this study, we prepared an asymmetric block copolyimide membrane with a defect-free skin layer using the dry-wet phase inversion process, and the gas transport properties of the asymmetric membranes were measured using a high vacuum apparatus equipped with a Baratron absolute pressure gauge at $76 \mathrm{cmHg}$ and $35^{\circ} \mathrm{C}$. We consider that it is important to 


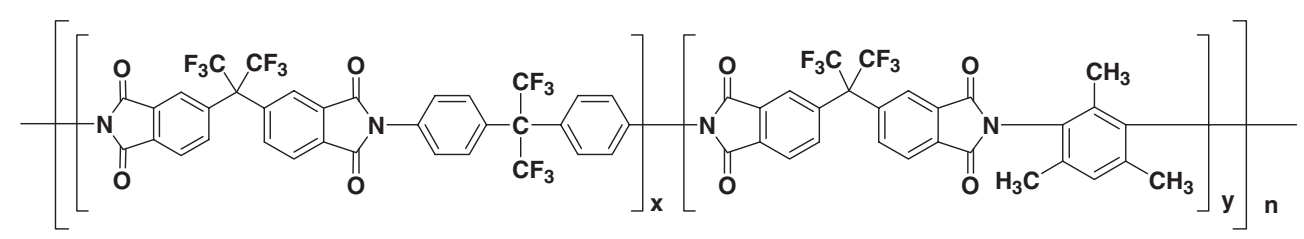

Figure 1. Chemical structure of block copolyimide.

elucidate how the phase separation change in the copolyimide affects the structure of the asymmetric membrane and the gas transport properties.

\section{EXPERIMENT}

\section{Materials}

2,2'-Bis(3,4-dicarboxyphenyl)hexafluoropropane dianhydride (6FDA) and 2,2'-bis(4-aminophenyl)hexafluoropropane (6FAP) were purchased from the Central Glass Co., (Saitama, Japan). 6FDA was purified by sublimation prior to use. 6FAP was recrystallized twice from ethanol solution prior to use. 2,4,6-Trimethyl-1,3-phenylenediamine (3MPA) was purchased from the Tokyo Kasei Co. (Tokyo, Japan) and purified by recrystallization from hexane solution.

\section{Snytheses of Homopolyimide, Random Copolyimide, and Block Copolyimides}

Two homopolyimides, 6FDA-6FAP and 6FDA-3MPA, were synthesized by the chemical imidization of poly (amic acid) precursors as reported in previous papers. ${ }^{21,22}$ The random copolyimides were also prepared by the same method as described for the homopolyimide preparation and derived from equimolar amounts of the dianhydride (6FDA) and diamines (6FAP/3MPA mol \%: 10/40). ${ }^{11}$

The block copolyimides were synthesized by a two-pot procedure, as reported in previous papers. ${ }^{23}$ In one flask, the dianhydride-terminated poly(amic acid) oligomers were prepared by the reaction of 6FAP and a calculated excess of 6FDA in $N, N^{\prime}$-dimethylacetamide (DMAc). In another flask, the diamine-terminated poly(amic acid) oligomers were prepared from 6FDA and an excess of 3MPA. BPI1 was prepared from $6.086 \mathrm{~g}(0.014 \mathrm{~mol})$ of 6FDA and $4.163 \mathrm{~g}(0.013 \mathrm{~mol})$ of 6FAP and from $21.62 \mathrm{~g}(0.049 \mathrm{~mol})$ of 6FDA and $7.499 \mathrm{~g}(0.050 \mathrm{~mol})$ of 3MPA. BPI 2 was prepared from $9.287 \mathrm{~g}(0.021 \mathrm{~mol})$ of 6FDA and $6.655 \mathrm{~g}(0.020 \mathrm{~mol})$ of $6 \mathrm{FAP}$ and from $35.04 \mathrm{~g}$ $(0.079 \mathrm{~mol})$ of 6 FDA and $11.999 \mathrm{~g}(0.080 \mathrm{~mol})$ of 3MPA. The feed ratio of $6 \mathrm{FAP} / 3 \mathrm{MPA}$ was $1 / 4$. After $12 \mathrm{~h}$, the diamineterminated oligomer solution was added to the dianhydrideterminated oligomer to synthesize the block copoly(amic acid). After stirring for $24 \mathrm{~h}$, the fluorinated block poly(amic acid) precursors were converted into the block copolyimide by chemical imidization with acetic anhydride and triethylamine. After a conversion of $24 \mathrm{~h}$, the block copolyimides were precipitated in methanol, washed several times with methanol, and recovered. Subsequently, the block copolyimides were dried in a vacuum oven at $150{ }^{\circ} \mathrm{C}$ for $15 \mathrm{~h}$. The chemical structure of the block copolyimide is shown in Figure 1.
${ }^{1} \mathrm{H}$ NMR measurements (FT NMR V4.0, JEOL, Tokyo, Japan) were performed to determine the ratio of 6FAP and 3MPA.

\section{Preparation of Asymmetric Copolyimide Membranes}

The asymmetric copolyimide membranes were prepared by a dry/wet phase inversion process. ${ }^{16-18}$ The polyimide solutions were made from $13 \mathrm{wt} \%$ polyimide, 58-62 wt $\%$ dichloromethane, $16.5-21.5 \mathrm{wt} \%$ 1,1,2-trichloroethane, and 6-10.5 wt $\%$ 1-butanol. After being filtered and degassed, the polyimide solutions were cast on a glass plate by a doctor-blade and then air-dried for $15 \mathrm{~s}$ at room temperature. After evaporation, the membranes were coagulated in methanol, washed for $12 \mathrm{~h}$, airdried for $24 \mathrm{~h}$ at room temperature, and finally dried in a vacuum oven at $150^{\circ} \mathrm{C}$ for $15 \mathrm{~h}$ to remove all of the residual solvents.

The viscosity of the casting solvent was measured using a cone and plate viscometer (RE-80 viscometer; Toki Sangyo Co., Ltd., Tokyo, Japan) at room temperature.

\section{Characteristics of Copolyimides}

The molecular weights $\left(M_{\mathrm{w}}\right.$ and $\left.M_{\mathrm{n}}\right)$ of the copolyimides were determined by gel-permeation chromatography (detector; Jasco 830-RI monitor) with THF as the solvent. A flow rate of $1.0 \mathrm{~mL} / \mathrm{min}$ was used, and the polyimide was dissolved in THF at a concentration of $0.005 \mathrm{wt} \%$. The molecular weights were estimated by comparing the retention times on a column (Shodex KF-805L) to those of standard polystyrene.

The cross sections of the asymmetric copolyimide membranes were observed using a scanning electron microscope (SEM, JXP-6100P, JEOL, Tokyo, Japan).

\section{Evaluation of Interaction Parameter}

The non-solvent-polymer interaction parameter $\left(\chi_{13}\right)$ is expressed by a simple equation as follows: ${ }^{24}$

$$
\chi_{13}=-\left\{\ln \left(1-\phi_{p}\right)+\phi_{p}\right\} / \phi_{p}{ }^{2}
$$

where $\phi_{p}$ is the volume fraction of the polymer and can be obtained by a swelling experiment. Dried strips of dense copolyimide membranes were immersed in non-solvents at $25^{\circ} \mathrm{C}$.

The solvent-polymer interaction parameter $\left(\chi_{23}\right)$ was obtained from the following equations as follows: ${ }^{25,26}$

$$
\begin{aligned}
& A_{2}=\frac{16 \pi N_{0}[\eta]}{M\left\{9.3 \times 10^{24}+4 \pi N_{0} c\left([\eta]-[\eta]_{\theta}\right)\right\}}\left\{1-\frac{[\eta]_{\theta}}{[\eta]}\right\} \\
& \chi_{23}=1 / 2-A_{2} \rho_{2}{ }^{2} v_{1}
\end{aligned}
$$

where $A_{2}$ is the second virial coefficient, $\pi$ is $3.14, N_{0}$ is Avogadro's constant, $c$ is the concentration $\left(\mathrm{g} / \mathrm{cm}^{3}\right),[\eta]$ is the 
intrinsic viscosity $\left(\mathrm{cm}^{3} / \mathrm{g}\right)$ of the copolymer in the given solvent, $[\eta]_{\theta}$ is its intrinsic viscosity under theta conditions, $M$ is the average copolymer molecular weight, $\rho$ is the density of the copolymer $\left(\mathrm{g} / \mathrm{cm}^{3}\right)$ and $v_{1}$ is the molar volume of the solvent $\left(\mathrm{cm}^{3} / \mathrm{mol}\right)$. Solution viscosities of copolyimides in dichloromethane and 1,1,2-trichloroethane at $25^{\circ} \mathrm{C}$ were measured with an Ubbelohde viscometer. The intrinsic viscosity was determined by the usual extrapolation to zero concentration. This Kok's method can predict the FloryHuggins interaction parameters from intrinsic viscosity, and the agreement between the parameters and those obtained at infinite dilutions from membrane osmometry or light scattering was within $2 \%$, on the average, as reported in the paper.

\section{Cloud Measurement}

The cloud time was determined using polyimide solutions made from $13 \mathrm{wt} \%$ copolyimide, $58 \mathrm{wt} \%$ dichloromethane, $21.5 \mathrm{wt} \%$ 1,1,2-trichloroethane, and $7.5 \mathrm{wt} \%$ 1-butanol. After being filtered and degassed, the polyimide solutions were cast on a glass plate with a doctor-blade and then air-dried for $15 \mathrm{~s}$ at room temperature. After evaporation, the membranes were coagulated in methanol. The cloud time was determined from the time when the initially clear membrane visually became cloudy during the wet phase inversion process.

\section{Gas Permeation Measurements}

The purities of the oxygen and nitrogen used in this study were $99.999 \%$. Polyimide membranes with a $0.7065 \times 10^{-3} \mathrm{~m}^{2}$ area were mounted in a stainless steel permeation cell. ${ }^{15}$ The gas permeability coefficients at $35^{\circ} \mathrm{C}$ and $76 \mathrm{cmHg}$ were determined using a high vacuum apparatus (Rika Seiki, Inc., $\mathrm{K}-315 \mathrm{H}$ ). The pressures on the upstream and downstream sides were detected using a Baratron absolute pressure gauge. The error in the permeability measurement was estimated to be less than $5 \%$.

Gas permeances of oxygen and nitrogen were measured with a high vacuum apparatus at $35^{\circ} \mathrm{C}$ and $76 \mathrm{cmHg}$. The apparent skin layer thickness of the asymmetric polyimide membranes was calculated from

$$
L=\frac{P}{Q}
$$

where $L[\mathrm{~cm}]$ is the apparent skin layer thickness, $P\left[\mathrm{~cm}^{3}\right.$ $\left.(\mathrm{STP}) \mathrm{cm} /\left(\mathrm{cm}^{2} \mathrm{sec} \mathrm{cmHg}\right)\right]$ is the gas permeability coefficient measured from a dense copolyimide flat membrane, and $Q$ $\left[\mathrm{cm}^{3}(\mathrm{STP}) /\left(\mathrm{cm}^{2} \mathrm{sec} \mathrm{cmHg}\right)\right]$ is the gas permeance of the asymmetric copolyimide membranes. $L$ was determined from the oxygen permeability coefficient.

\section{RESULTS AND DISCUSSION}

\section{Characteristics of Block Copolyimides}

The block copolyimides with the different block chain lengths were synthesized by chemical imidization from the precursor as reported in previous papers. ${ }^{23}$ The $\mathrm{X}$ and $\mathrm{Y}$ values as the apparent block chain length were calculated from the
Table I. Characteristics of random and block copolyimides

\begin{tabular}{cccccc}
\hline Copolyimide & type & $\begin{array}{c}\text { Molar ratio } \\
\text { (6FAP:3MPA) }\end{array}$ & $\begin{array}{c}\text { Apparent block } \\
\text { chain }^{\text {a) }} \text { length (x:y) }\end{array}$ & $M_{\mathrm{w}}$ & $M_{\mathrm{w}} / M_{\mathrm{n}}$ \\
\hline RPI & Random & $1: 4$ & - & $2.6 \times 10^{5}$ & 2.1 \\
BPI1 & Block & $1: 4$ & $17: 90$ & $2.1 \times 10^{5}$ & 2.0 \\
BPI2 & Block & $1: 4$ & $32: 170$ & $2.9 \times 10^{5}$ & 2.3 \\
\hline
\end{tabular}

molecular weights of the dianhydride-terminated poly(amic acid) oligomers and the diamine-terminated poly(amic acid) oligomers. These poly(amic acid) oligomers were converted to the polyimide oligomers by chemical imidization and the molecular weights of their oligomers were determined by gelpermeation chromatography. Table I shows the apparent block chain length, molecular weight, and polydispersity of a random copolyimide (RPI) and the block copolyimides (BPI1 and BPI2). The ratio of $6 \mathrm{FAP} / 3 \mathrm{MPA}$ and the degree of imidization of the copolyimides were determined by ${ }^{1} \mathrm{H}$ NMR spectroscopy (data not shown). The ratio was approximately $1 / 4$. ${ }^{1} \mathrm{H}$ NMR spectra of poly(amic acid)s showed two peaks that were located at $13 \mathrm{ppm}$ due to the carboxylic acid and at $10.4 \mathrm{ppm}$ due to the amide groups. However, these peaks completely disappeared after imidization. The results of ${ }^{1} \mathrm{H}$ NMR spectroscopy supported the belief that the copolyimides synthesized by chemical imidization were completely imidized. The copolyimides were soluble in chloroform, dimethylsulfoxide, DMAc, $N, N$-dimethylformamide, and THF. The membranes were optically clear and mechanically stable.

\section{Gas Transport Properties of Dense Block Copolyimide Membranes}

Figure 2 shows the gas permeability coefficients and gas selectivities of the dense random and block copolyimide membranes at $76 \mathrm{cmHg}$ and $35^{\circ} \mathrm{C}$. In general, the gas permeability coefficients of the copolymer membranes are estimated using the semilogarithmic additivity rule: ${ }^{27}$

$$
\ln \mathrm{P}=\phi_{1} \ln \mathrm{P}_{1}+\phi_{2} \ln \mathrm{P}_{2}
$$

where $\phi_{1}$ is the volume fraction and subscripts 1 and 2 refer to the two-component polymers. The gas permeabilities of the block copolyimide membranes indicated nearly similar values compared to that of a random copolyimide and were consistent with those calculated from the semilogarithmic additivity rule.

On the other hand, the gas selectivities of the random and block copolyimide membranes are estimated using the following equation:

$$
\ln \left(\frac{P_{A}}{P_{B}}\right)=\phi_{1} \ln \left(\frac{P_{A}}{P_{B}}\right)_{1}+\phi_{2} \ln \left(\frac{P_{A}}{P_{B}}\right)_{2}
$$

The gas selectivities of all the block copolyimide membranes were similar to those calculated using equation 6 and were approximately 3.6. That is, the gas transport properties of the dense random and block copolyimide membranes depend on only the ratio of the two-component polymers, and a great difference in the properties for the membranes was not shown. 
(a)

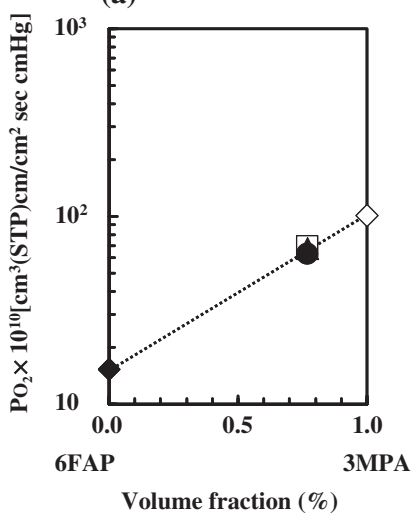

(b)

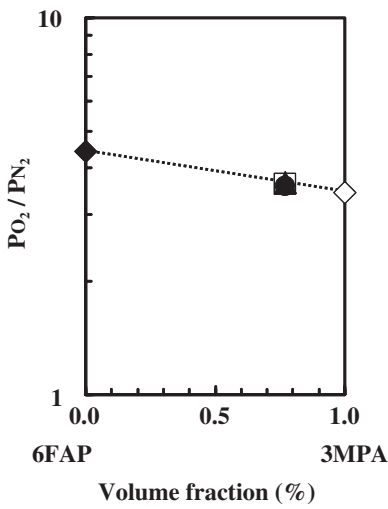

Figure 2. $\mathrm{O}_{2}$ permeability coefficients $(\mathrm{a})$ and $\left(\mathrm{PO}_{2} / \mathrm{PN}_{2}\right)$ selectivities $(b)$ for dense random and block copolyimid membranes at $76 \mathrm{cmHg}$ and $35^{\circ} \mathrm{C}$ : 6FDA-6FAP $(\diamond)$; 6FDA-3MPA $(\diamond)$; RPI $(\square)$; BPI1 $(\Delta)$; BPI2 (O).

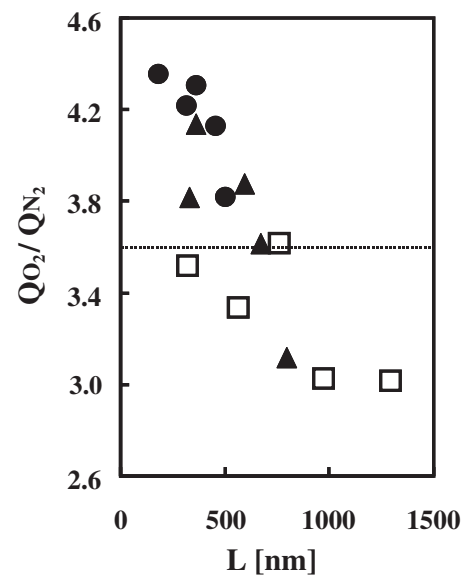

Figure 3. Apperent skin layer thickness (L) and $\left(Q_{2} / \mathrm{QN}_{2}\right)$ selectivity of asymmetric random and block copolyimid membranes at $76 \mathrm{cmHg}$ and $35^{\circ} \mathrm{C}$ : RPI ( $\square$ ); $\operatorname{BPI} 1(\mathbf{\Delta})$; $\operatorname{BPI} 2(\mathbf{O})$.

Gas Transport Properties of Asymmetric Block Copolyimide Membranes

Figure 3 shows the effect of the apparent skin layer thickness on the $\mathrm{O}_{2} / \mathrm{N}_{2}$ selectivity for the asymmetric random and block copolyimide membranes at $35^{\circ} \mathrm{C}$ and $76 \mathrm{cmHg}$. The dense copolyimide membrane indicated an $\mathrm{O}_{2} / \mathrm{N}_{2}$ selectivity of 3.6 and an $\mathrm{O}_{2}$ permeability coefficient of $6.7 \times 10^{-9}$ $\left[\mathrm{cm}^{3}(\mathrm{STP}) \mathrm{cm} /\left(\mathrm{cm}^{2} \mathrm{sec} \mathrm{cmHg}\right)\right]$. The skin layer thickness of the asymmetric membrane was calculated from the oxygen permeability coefficient. The averages of $\mathrm{O}_{2} / \mathrm{N}_{2}$ selectivity for the asymmetric RPI, BPI1, and BPI2 membranes were 3.3, 3.7, and 4.1, respectively; hence, the selectivity of the asymmetric random copolyimide membranes was slightly lower than that for the dense membrane. Lower gas selectivity of the asymmetric membranes can be the result of defects in the skin layer or enhanced free volume in the skin layer. However, defects in the skin layer were not accepted due to the slight decrease in the gas selecitivty compared to that of the dense random copolyimide membrane. On the other hand, the
Table II. Gas transport properties and apparent skin layer thickness for asymmetric random and block copolyimide membranes at $76 \mathrm{cmHg}$ and $35^{\circ} \mathrm{C}^{\mathrm{a}}$

\begin{tabular}{ccccc}
\hline Copolyimide & $\begin{array}{c}\text { Apparent } \\
\text { skin layer } \\
\text { thickness } \\
(\mu \mathrm{m})\end{array}$ & $\begin{array}{c}\mathrm{QO}_{2} \\
(\mathrm{GPU})^{\mathrm{b}}\end{array}$ & $\mathrm{QO}_{2} / \mathrm{QN}_{2}$ & $\mathrm{QN}_{2} / \mathrm{QCH}_{4}$ \\
\hline $\mathrm{RPI}$ & 1.2 & 57 & 3.0 & 1.22 \\
$\mathrm{BPI}$ & 0.84 & 80 & 3.6 & 1.30 \\
$\mathrm{BPI} 2$ & 0.23 & 270 & 4.3 & 1.32 \\
\hline
\end{tabular}

a Asymmetric membranes were made from $13 \mathrm{wt} \%$ copolyimide, $58 \mathrm{wt} \%$ DCM, $21.5 \mathrm{wt} \% \mathrm{TCE}$, and $7.5 \mathrm{wt} \%$ Butanol. Evaporation time was $15 \mathrm{~s}$.

${ }^{\mathrm{b}} \mathrm{GPU}=1 \times 10^{-6}\left[\mathrm{~cm}^{3}(\mathrm{STP}) / \mathrm{cm}^{2} \mathrm{~s} \mathrm{cmHg}\right]$.

enhanced free volume in the skin layer results in a decrease in the inter- or intramolecular polymer chain packing. The increase in free volume might lead to higher gas permeance and lower gas selectivity. In contrast, the selectivity of the asymmetric block copolyimide membranes was similar to or greater than that determined for a solvent-cast dense membrane, which indicates that the permeation of the asymmetric membrane is predominantly carried out by a solution-diffusion mechanism and that the surface skin layer is essentially defectfree. The gas selectivity of the asymmetric copolyimide membranes increased in the order RPI $<$ BPI $<$ BPI2.

Table II shows the typical results of the gas transport data for the asymmetric RPI, BPI1, and BPI2 membranes. The asymmetric block copolyimide membranes indicated higher gas permeance and selectivity than the asymmetric random copolyimide membrane. In particular, the asymmetric BPI2 membrane had both excellent gas permeance and selectivity, and the apparent skin layer thickness of the membrane was $230 \mathrm{~nm}$. We obtained two important results for the gas transport properties of the asymmetric block copolyimide membranes from Figure 3 and Table II. One important result was that the phase separation in the block copolyimide solution instantaneously occurred so that the skin layer of the asymmetric block copolyimide membrane became thinner than that of the asymmetric random copolyimide membrane and the gas permeance of the asymmetric block copolyimide membrane had a high value. Another result was that the gas selectivity of the asymmetric block copolyimide membrane surpassed those of the asymmetric random copolyimide membrane.

Figure 4 shows the results of the SEM observations of the asymmetric copolyimide membranes made from the dry-wet inversion. The skin layer thickness of the asymmetric membranes decreased in the following order: RPI > BPI1 > BPI2, as shown in Table II. The cross-sectional structure of all the asymmetric membrane consisted of a thin skin layer and a porous substructure. The asymmetric membranes made from the block copolyimides indicated sponge-like structures characterized by the presence of finger-voids, while the membrane made from the random copolyimide had only a sponge-like structure. In general, the finger-voids in the membrane were formed by the instantaneous demixing between the polymer solution and the coagulant. ${ }^{28,29}$ The SEM results might suggest that the exchange rate between the polymer solution and the coagulant in BPI2 was the fastest among the copolyimides. 


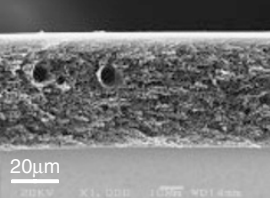

RPI

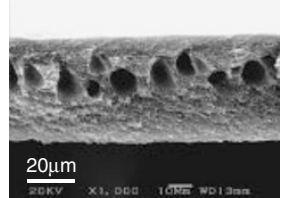

BPI1

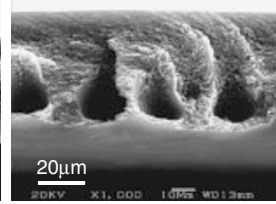

BPI2
Figure 4. SEM photographs of cross section of asymmetric random and block copolyimide membranes. (Asymmetric membranes were made from 13 wt $\%$ copolyimide, 58 wt $\%$ DCM, 21.5 wt $\%$ TCE, and $7.5 \mathrm{wt} \%$ Butanol. Evaporation time was $15 \mathrm{~s}$.

As is apparent from Table II and Figure 3, the gas permeance and the gas selectivity in the asymmetric membranes increased with the decreasing skin layer thickness. The gas selectivities of the asymmetric membrane prepared by the block copolyimide surpassed those of the random membranes. The gas transport behavior obtained in this study was in accordance with those of the asymmetric polyimide membranes reported in the previous papers. ${ }^{18}$ We have already demonstrated that the asymmetric polyimide membrane with a thinner surface skin layer formed a more packed structure and that the packed structure in the surface skin layer provided a high size and shape discrimination between the gas molecules. ${ }^{18} \mathrm{We}$ believe that the more packed structure formed in the asymmetric copolyimide membrane with a thinner surface skin layer is also responsible for the thickness-dependence of the gas selectivity obtained in this study.

In general, for a rubbery polymer such as natural rubber and silicone rubber, the broad distribution of segmental motions in the polymer produces a correspondingly broad distribution of intersegmental gas sizes responsible for gas diffusion, so that the permeability to gases decreases in the order, $\mathrm{PCO}_{2}>\mathrm{PCH}_{4}>\mathrm{PO}_{2}>\mathrm{PN}_{2}$. On the other hand, stiffer polymers such as aromatic polyimides behave more like "molecular sieves," 30 so that the permeability to gases decreases in the order, $\mathrm{PCO}_{2}>\mathrm{PO}_{2}>\mathrm{PN}_{2}>\mathrm{PCH}_{4}$; this is the order of increasing "kinetic diameter" of the penetrant molecules. The random and block copolyimide membranes were more permeable to $\mathrm{N}_{2}$ than to $\mathrm{CH}_{4}$, and their membranes indicated the gas transport like "molecular sieves." The $\mathrm{N}_{2} /$ $\mathrm{CH}_{4}$ selectivity at $35^{\circ} \mathrm{C}$ for the asymmetric RPI, BPI1, and BPI2 membranes shown in Table II were 1.22, 1.30, and 1.32, respectively. We believe that the molecular sieving-like effect induced by the more packed structure in the skin has a significant influence on the gas permeability and selectivity, indicating that a skin layer provides a high size and shape discrimination between the gas molecules. In addition, these results may be related to mircophase or nanophase separation of block copolyimide. However, this argument will be elucidated in the further study.

\section{Effect of Phase Separation on Formation of Asymmetric Membrane}

As is apparent from the SEM micrographs in Figure 4, it can be concluded that the transition from delayed to instantaneous
Table III. Viscosity of casting solvent at $25^{\circ} \mathrm{C}$ and cloud time of dry/wet process

\begin{tabular}{ccc}
\hline Copolyimide & Viscosity $(\mathrm{cP})^{\mathrm{a}}$ & ${\text { Cloud point }(\mathrm{s})^{\mathrm{a}, \mathrm{b}}}^{\mathrm{a}}$ \\
\hline $\mathrm{RPI}$ & $4.98 \times 10^{2}$ & 16.6 \\
BPI1 & $2.56 \times 10^{2}$ & 14.6 \\
BPI2 & $6.15 \times 10^{2}$ & 10.2 \\
\hline
\end{tabular}

${ }^{a}$ Casting solvent were made from $13 w t \%$ copolyimide, $58 w t \% \mathrm{DCM}$, $21.5 \mathrm{wt} \% \mathrm{TCE}$, and $7.5 \mathrm{wt} \%$ Butanol. ${ }^{\mathrm{b}}$ Evaporation time was $15 \mathrm{~s}$.

Table IV. Interaction parameters for copolyimide/solvent/non-solvent

\begin{tabular}{ccccc}
\hline \multirow{2}{*}{ Copolyimide } & $\chi_{13}$ & & \multicolumn{2}{c}{$\chi_{23}$} \\
\cline { 2 - 2 } \cline { 5 - 5 } & Butanol & & Dichloromethane & Trichloroethane \\
\hline RPI & 0.82 & & 0.47 & 0.43 \\
BPI1 & 0.77 & & 0.46 & 0.42 \\
BPI2 & 0.74 & & 0.46 & 0.44 \\
\hline
\end{tabular}

$\chi_{13}$ : Interaction between poor solvent and polymer. $\chi_{23}$ : Interaction between good solvent and polymer.

onset of phase separation, obtained by varying the type of copolyimide, is responsible for the appearance of the fingervoids. That is, the random copolyimide in the casting solution caused a considerable delay time for phase separation so that the asymmetric membrane showed a sponge-like structure. In contrast, in the case of the block copolyimides, the delay time decreased so that the phase separation in the polymer solution instantaneously occurred, and the asymmetric membrane is considered to form sponge-like structures characterized by the presence of finger-voids. Table III shows the viscosity of the casting solvent and the cloud time determined from the time when the initially clear membrane visually becomes cloudy during the wet phase inversion process after a $15 \mathrm{~s}$ drying process. In general, there is correlation between the cloud time of the polymer solution and the phase separation of the polymer, and a short cloud time expresses the instantaneous phase separation in the polymer solution. As shown in Table III, the time depends on the kinds of copolyimide and decreased with an increase in the number of finger-voids observed for the asymmetric copolyimide membranes. These results also demonstrated that the copolyimide structure had a significant influence on the instantaneous phase separation of the polymer. On the other hand, there was no correlation between the viscosity of the casting solvent and the fingervoids in the asymmetric membrane.

The binary interaction parameters for the copolyimide/ solvent/non-solvent system have been well investigated to examine the phase inversion occurring in the coagulant medium. To understand the formation mechanism of the asymmetric copolyimide membranes, we estimated the parameters. The binary interaction parameters of non-solventcopolyimide $\left(\chi_{13}\right)$ and solvent-copolyimide $\left(\chi_{23}\right)$ are summarized in Table IV. The solvents are dichloromethane (DCM) and 1,1,2-trichloroethane (TCE). Non-solvent means the butanol contained in the casting solution, not the methanol for coagulation. As is apparent from Table IV, $\chi_{23}$ values 
Butanol

RPI
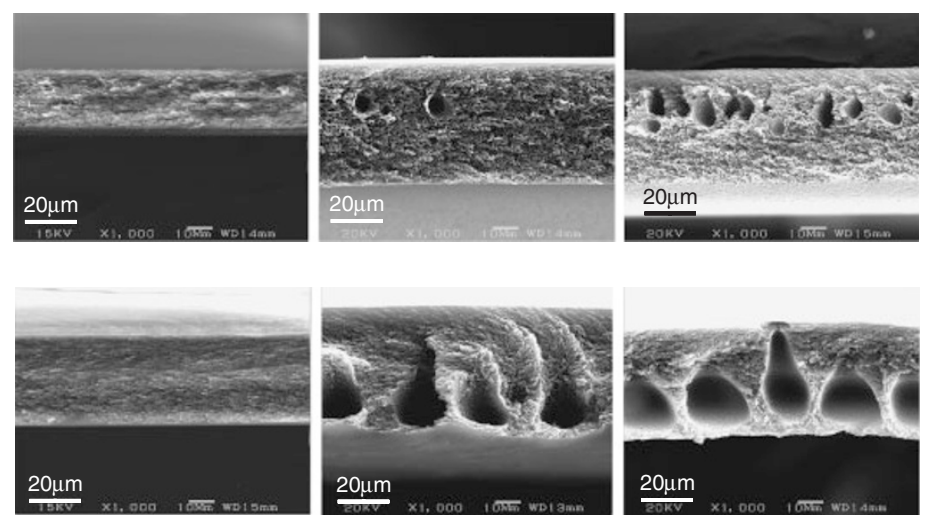

Figure 5. SEM photographs of cross section of asymmetric random and block copolyimid membranes. (Asymmetric membranes were made from $6,7.5$, and $9 \mathrm{wt} \%$ Butanol. Evaporation time was $15 \mathrm{~s}$.)

calculated from the copolyimide and solvent were almost constant, indicating that the influence of $\chi_{23}$ on the structure of the asymmetric membrane is negligible. In contrast, $\chi_{13}$ values as an interaction parameter between the butanol and the copolyimide depended on the copolyimide structures. In general, a large $\chi_{13}$ indicates a low compatibility of the butanol-copolyimide interaction and a small $\chi_{13}$ indicates the high mutual affinity of butanol and the copolyimide. We consider that $\chi_{13}$ might have an influence on the phase inversion occurring in the coagulant medium.

To elucidate the influence of butanol in the casting solution on the structure of the asymmetric copolyimide membranes, we prepared the asymmetric membranes with the different butanol amounts in using the dry-wet phase inversion process. As is apparent from Figure 5, the size of the finger-voids in the membranes became greater as the butanol amount increased, and the number of finger-voids also increased with the butanol amount. The finger-voids of the BPI1 membrane also indicated the similar trend (data not shown). These findings indicated that the phase separation might rapidly occur due to the increased butanol amount in the polymer solution.

Table V shows the effect of butanol amount on the gas transport properties of the asymmetric RPI, BPI1, and BPI2 membranes. The apparent skin layer thickness of the asymmetric membranes strongly depended on the butanol amount and decreased with an increase in butanol amount, supporting the belief that the phase separation rapidly occurs due to the increased butanol amount in the polymer solution. However, the BPI 1 and BPI 2 membranes at $9 \mathrm{wt} \%$ butanol and the RPI membrane at $10.5 \mathrm{wt} \%$ butanol showed an $\mathrm{O}_{2} / \mathrm{N}_{2}$ selectivity of 1 , respectively, and the low gas selectivities of the membranes can be the result of pores (defects). That is, the skin layer pores are defined as providing gas permeation by a Knudsen or viscous flow process.

The above results clearly indicate that the structure of the fluorinated copolyimide has a significant influence on the formation of asymmetric membranes made by the dry-wet phase inversion process. Furthermore, it is important to note
Table V. Effect of butanol amount on gas transport properties for asymmetric random and block copolyimide membranes at $76 \mathrm{cmHg}$ and $35^{\circ} \mathrm{C}$

\begin{tabular}{ccccc}
\hline Copolyimide & $\begin{array}{c}\text { Butanol } \\
(\mathrm{wt} \%)\end{array}$ & $\mathrm{QO}_{2}(\mathrm{GPU})^{\mathrm{a}}$ & $\mathrm{QO}_{2} / \mathrm{QN}_{2}$ & $\mathrm{~L}(\mathrm{~nm})$ \\
\hline $\mathrm{RPI}$ & 6 & 7.5 & 3.6 & 9270 \\
$\mathrm{BPI} 1$ & 6 & 68 & 3.6 & 1000 \\
$\mathrm{BPI} 2$ & 6 & 100 & 3.8 & 620 \\
$\mathrm{RPI}$ & 7.5 & 57 & 3.0 & 1200 \\
$\mathrm{BPI} 1$ & 7.5 & 80 & 3.6 & 840 \\
$\mathrm{BPI} 2$ & 7.5 & 270 & 4.3 & 230 \\
$\mathrm{RPI}$ & 9 & 170 & 3.5 & 410 \\
$\mathrm{BPI} 1$ & 9 & 5500 & 1.0 & - \\
$\mathrm{BPI}$ & 9 & $-\mathrm{b}$ & 1.0 & - \\
$\mathrm{RPI}$ & 10.5 & - & 1.0 & - \\
BPI1 & 10.5 & - & 1.0 & - \\
BPI2 & 10.5 & - & 1.0 & - \\
\hline
\end{tabular}

${ }^{\mathrm{a}} \mathrm{GPU}=1 \times 10^{-6}\left[\mathrm{~cm}^{3}(\mathrm{STP}) / \mathrm{cm}^{2} \mathrm{~s} \mathrm{cmHg}\right]{ }^{\mathrm{b}}$ Out of measurement.

that the optimized process generates an asymmetric membrane with a defect-free and ultrathin skin layer.

\section{CONCLUSIONS}

Fluorinated block copolyimides with different block chain lengths were successfully synthesized by chemical imidization using a two-pot procedure, and the asymmetric block copolyimide membranes with a defect-free and ultrathin skin layer were prepared by the dry-wet phase inversion process. We demonstrated that the gas transport properties of the asymmetric membranes depended on the copolyimide structure. The phase separation in the block copolyimide solution instantaneously occurred so that the skin layer of the asymmetric block copolyimide membrane became thinner than that of the asymmetric random copolyimide membrane and the gas permeance of the asymmetric block copolyimide membrane had a high value. In addition, the gas selectivity of the asymmetric block copolyimide membrane surpassed those of the asymmetric random copolyimide membrane. 
The formation of the asymmetric copolyimide membrane had an influence on the instantaneous phase separation of the copolyimide. The random copolyimide in the casting solution caused a considerable delay time for phase separation so that the asymmetric membrane showed a thicker skin layer. In contrast, in the case of the block copolyimides, the delay time decreased so that the phase separation in the polymer solution instantaneously occurred, and the asymmetric membrane had a thinner skin layer. We consider that an interaction between the butanol and the copolyimide might have an influence on the phase inversion occurring in the coagulant medium.

Acknowledgment. This work was partially supported by grant from the Ministry of Education, Culture, Sports, Science and Technology.

Received: May 1, 2009

Accepted: July 8, 2009

Published: September 10, 2009

\section{REFERENCES}

1. W. J. Koros and D. R. B. Walker, Polym. J., 23, 481 (1991).

2. S. A. Stern, J. Membr. Sci., 94, 1 (1994).

3. P. P. Nikunj and J. S. Richard, Macromolecules, 37, 2829 (2004).

4. S. J. Metz, M. H. V. Mulder, and M. Wessling, Macromolecules, 37, 4590 (2004).

5. J. Y. Lai, C. Y. Shih, and F. C. Lin, Polym. J., 26, 665 (1994).

6. V. I. Bondar, B. D. Freeman, and I. Pinnau, J. Polym. Sci., Part B: Polym. Phys., 38, 2051 (2000).

7. K. Nakajima, S. Nagaoka, and H. Kawakami, Polym. Adv. Technol., 14, 433 (2003).

8. R. L. Burns and W. J. Koros, Macromolecules, 36, 2374 (2003).

9. A. M. Kratochvil and W. J. Koros, Macromolecules, 41, 7920 (2008).

10. B. W. Chun, C. Ishizu, H. Itatani, K. Haraya, and Y. Shindo,
J. Polym. Sci., Part B: Polym. Phys., 32, 1009 (1994).

11. H. Kawakami, M. Mikawa, and S. Nagaoka, J. Membr. Sci., 163, 167 (1999).

12. W.-H. Lin, R. H. Vora, and T.-S. Chung, J. Polym. Sci., Part B: Polym. Phys., 38, 2703 (2000).

13. Y. Oishi, K. Itoya, M. Kakimoto, and Y. Imai, Polym. J., 21, 771 (1989).

14. T. P. Bender and Z. Y. Wang, J. Polym. Sci., Part A: Polym. Chem., 38, 3991 (2000).

15. I. Pinnau, J. W. Wind, and K.-V. Peinamann, Ind. Eng. Chem. Res., 29, 2028 (1990).

16. I. Pinnau and W. J. Koros, J. Membr. Sci., 71, 81 (1992).

17. H. Kawakami, M. Mikawa, and S. Nagaoka, J. Appl. Polym. Sci., 62, 965 (1996).

18. H. Kawakami, M. Mikawa, and S. Nagaoka, Macromolecules, 31, 6636 (1998).

19. M. Niwa, H. Kawakami, S. Nagaoka, T. Kanamori, and T. Shinbo, J. Membr. Sci., 171, 253 (2000).

20. M. Niwa, H. Kawakami, T. Kanamori, T. Shinbo, A. Kaito, and S. Nagaoka, Macromolecules, 34, 9039 (2001).

21. H. Kawakami, J. Anzai, and S. Nagaoka, J. Appl. Polym. Sci., 57, 789 (1995).

22. H. Kawakami, M. Mikawa, and S. Nagaoka, J. Membr. Sci., 118, 223 (1996).

23. M. Niwa, S. Nagaoka, and H. Kawakami, J. Appl. Polym. Sci., 100, 2436 (2006).

24. M. H. V. Mulder and C. A. Smolders, J. Membr. Sci., 17, 289 (1984).

25. C. M. Kok and A. Rudin, J. Appl. Polym. Sci., 27, 353 (1982).

26. J. Y. Kim, H. K. Lee, K. J. Baik, and S. C. Kim, J. Appl. Polym. Sci., 65, 2643 (1997).

27. A. E. Barnabeo, W. S. Creasy, and L. M. Robeson, J. Polym. Sci., 13, 1979 (1975).

28. J. G. Wijmans, J. Kant, M. H. V. Mulder, and C. A. Smolders, Polymer, 26, 1539 (1985).

29. P. Witte, P. J. Dijkstra, J. W. A. Berg, and J. Feijen, J. Membr. Sci., 117, 1 (1996).

30. T. H. Kim, W. J. Koros, G. R. Husk, and K. C. O'Brien, J. Membr. Sci., 34, 1767 (1987). 